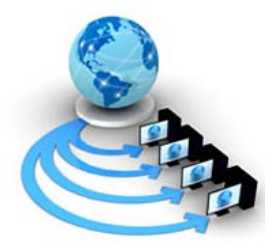

Volume 9, No. 3, May-June 2018

International Journal of Advanced Research in Computer Science

RESEARCH PAPER

Available Online at www.ijarcs.info

\title{
SOWING AND TILLING ROBOT CONTROLLED BY IR SENSORS
}

\author{
K. NishanthRao, G Shravan Kumar²B, Sowjanya, N. Nithinkumar, P. Gnanender,G.Rakesh \\ Assistant professor ${ }^{1}$, Associate Professor ${ }^{2}$, under graduate \\ Dept. of Electronics And Communication Engineering,MLR Institute of Technology, Hyderabad, India
}

\begin{abstract}
During the farming, the major task is to till the land and sow the seeds. We can see that many farmers employing a person for sowing the seeds which needs a lot of man power. In order to avoid these problems, we are introducing sowing and tilling robot[1]. The robot is controlled by IR sensor and is developed by 8051 micro controller. This robot will have two wheels to move which are run by two motors and controlled by a micro controller. To sow the seeds we use a gear which will pick the seeds and drop them through a hollow tube. As the tooth of the gear is equally spaced, the seeds we sow will be with equal distance. These robots are fully automated and have sensors to detect the obstacles. After sowing the seeds, the arm attached to this robot will cover the tilled soil. This paper helps the farmers to reduce the labor power and other machine power.
\end{abstract}

Key-words-- 8051 micro controller, motors, IR sensors, mud leveler

\section{METHODOLOGY}

\section{INTRODUCTION}

The design of applying robotics machinery[4] in agriculture[2] is very novel. In farming, the prospect for robot enhanced production arehuge - and the robot are appear on farm in a variety of guises and in growingstatistics. We can be expecting the robots performing farmingoperationseparately[8] such as tilling the ground, seed sowing and level the land. This paper objective is to build a robot vehicle[5] which can plow the soil, place the seeds, and seal the mud, these entire systems of the robot mechanism with the battery and autonomously. To diminishperson effort in the farming field with the use of small robot. To perform all 3 operations at single time, hence increasesmanufacture and saves time. To complete large amount of work in less time.

\section{LITERATURE SURVEY}

The introduction of robots in the field of agriculture was done with the intention to reduce the hard work and use of heavy machines like tractors, harvestors, etc. at the very beginning an agribot[7] was developed which will sow the seeds in tilled land. Later, the additional features like tilling the land, levelling the land, watering the plants came into existence using many modern and updated technologies. Previously, an agricultural robot wasdeveloped based on the DTMF[5] technology. This agricultural robot was able to perform the two operations Tilling the land and Sowing the seeds. All the motors and the sowing and tilling arms are controlled by the remote which made the project a complex one with many switches.

Our project sowing and tilling robot, is an advancement over the previous project. It is an autonomous robot which is controlled by IR sensor input and the main component is Atmega 8051[8-10] micro controller. As this is an autonomous robot, there is no need of coplex switching and controlling.
The base framework is prepared for the robot with four wheels drivenbyDC motors. One end of the structure, tilling arm is fitted which is also driven by DC motor and design is made to dig the soil.[6] Funnel is made by the sheet metal, to store the seeds and the seeds pour through the funnel through the drilled hole on the shaft to the tilledsoil.On the other end leveler is fitted to close the soil on the seeds. All the DC motors are driven by the L293D motor drivers. The whole robot requires the $12 \mathrm{v}$ battery to operate the system.IR transmitter and IR receiver is used to control the operation of the vehicle.[9] Thepaper is virtually simulated in PROTEUS and then dumped in to the micro controller.

\section{Block Diagram :}

Our project mainly depends on the timing behavior of 8051 controller. Here in the instruction set given to the controller is given considering the timing characteristics and properties of the controller. When a regulated power supply is given to the robot, it starts moving. The motors attached to the tilling, sowing and levellingarms also starts which ultimately performs the three assigned tasks. When the timer exceeds the given time period, the motors attached to the wheels and sowing arm will stop and the motors attached to sowing and levelling arms starts rotating in reverse direction[3] in order to remove the mud in them.When an IR sensor input is detected, i.e, if there is any obstacle in the way of robot, the robot turns right side and continues the tasks. 


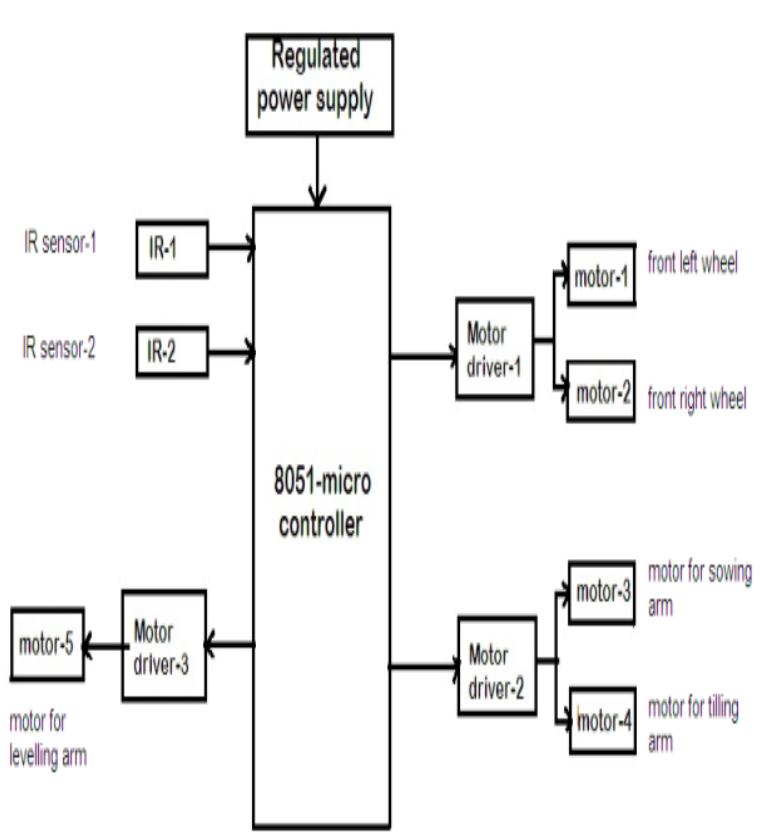

Fig 1: block diagram of Sowing and Tilling robot

\section{Simulated Design:}

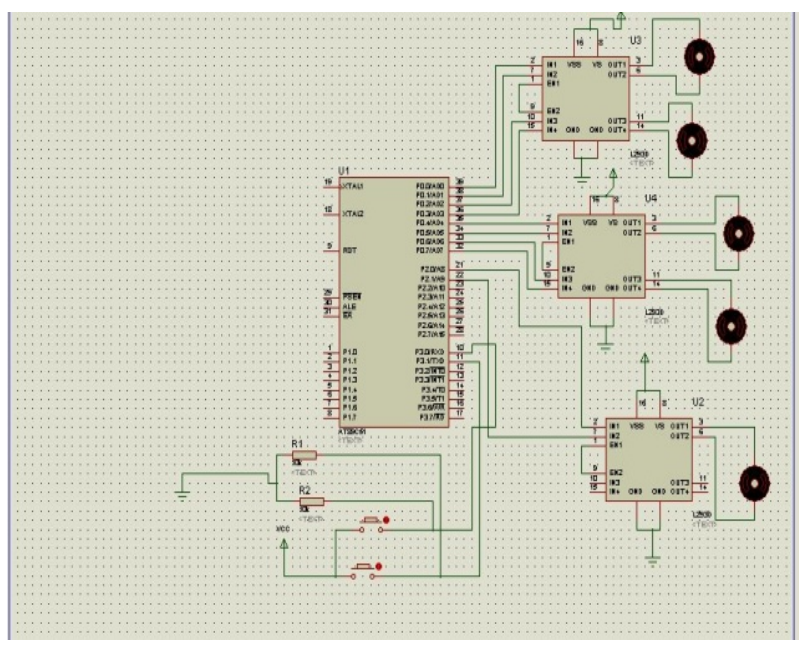

Fig 2: simulated Design

The virtually simulated design of sowing and tilling robot

\section{RESULT:}

Tilling arm of Robot:

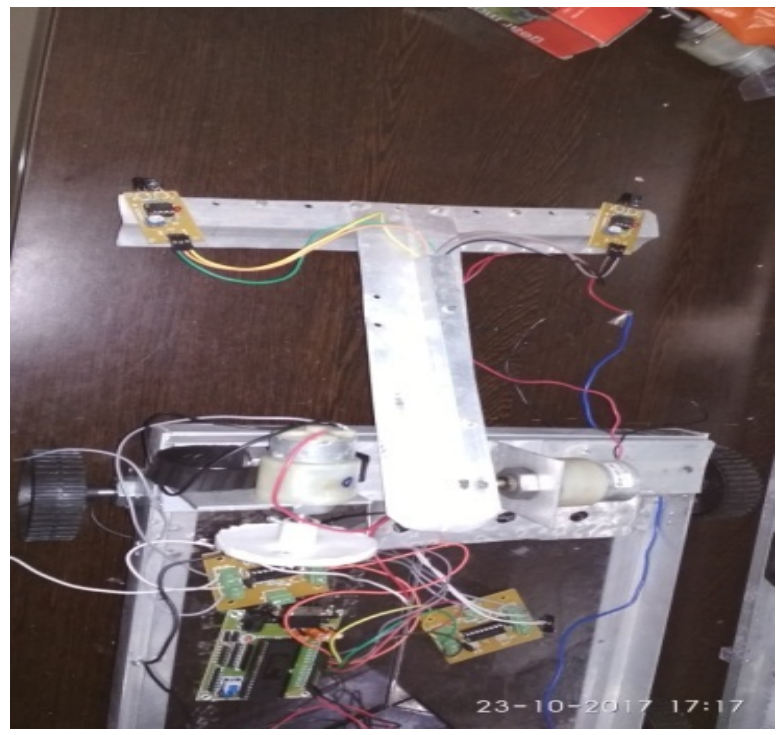

Fig 3: Proto type model

The tilling arm is driven by the DC motorwhich is driven by L293D motor driver[4]. $12 \mathrm{v}$ is supplied to the motor driver with battery. When the timer[8] reaches the given value, themotor rotates in opposite direction for asmaller duration[11]. When an obstacle isdetected by IR sensors, the motor turns to itsright-side.

\section{Sowing arm of Robot:}

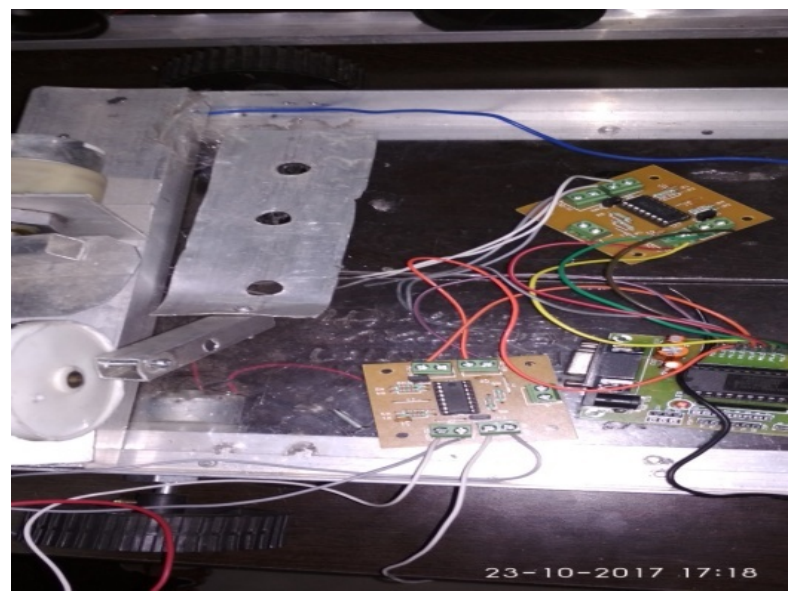

Fig 4: Sowing arm of robot

A storage box is placed where we can storethe seeds and it has holes at the bottom. Theholes will be opened with the help of a shaftattached to the motor[12] which moves to and froand allows seeds to fall through the holes[6].

Leveling arm of Robot: 


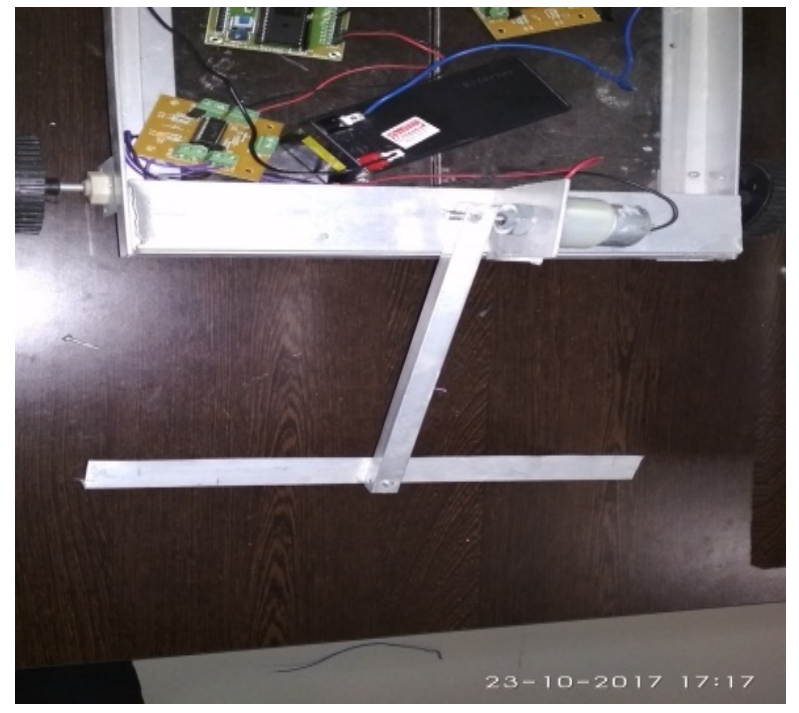

Fig 5: Leveling arm of robot

The leveling arm of robot is driven by DCmotor which is run by a motor driver L293D. similar to the tilling arm, the leveling arm rotates in opposite direction after given time. Thus allows the mud stuck to fall.

Finalisined Sowing and Tilling Robot:

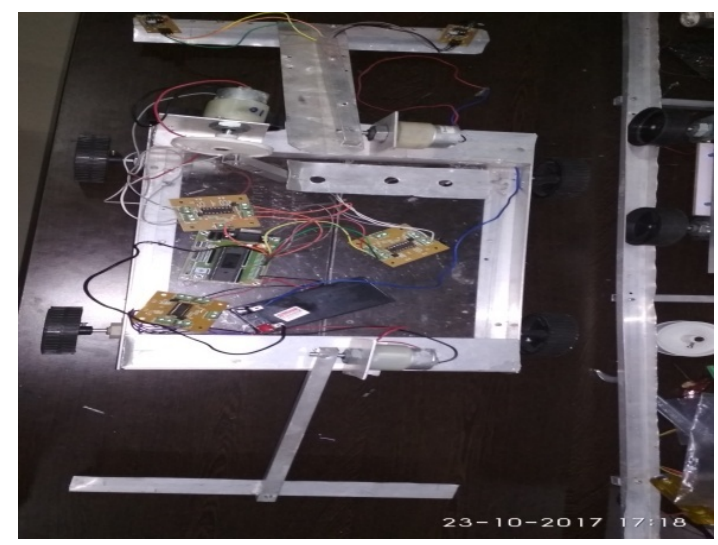

Fig 6: Finalisined Sowing and Tilling Robot

\section{CONCULSION}

This roboticfarmingmachine[1] is designed to facilitate the farmers to reduce human effort in the agricultural field for sowing the seedsand improving the production, with its multitasking. These robots are fully automated and have sensors to detect the obstacles. After sowing the seeds, the arm attached to this robot will cover the tilled soil.

\section{REFERENCES}

[1] Tillett, N.D., Hague, T. and Marchant, J.A.(1998) A robotic system for plant scale husbandry. Journal of Agricultural Engineering Research, 69, 169-178

[2] Blackmore, S. (2007). A systems view of agricultural robotics. Precision Agriculture conference, Wageningen Academic Publishers, the Netherlands. pp. 23-31

[3] XueJinlin, Xu Liming, "Autonomous Agriculture Robot and its row guidance", International Conference on Measuring Technology, 2010.

[4] Fast motion planning for multiple moving robots - S.J. Buckley

[5] AmritanshuSrivastava, Shubham Vijay, AlkaNegi, Akash Singh, "DTMF Based Intelligent Farming Robotic Vehicle,” International Conference on Embedded Systems (ICES 2014), 978-1-4799-5026-3, IEEE 2014. AmritanshuSrivastava, Shubham Vijay, AlkaNegi, Akash Singh, "DTMF Based Intelligent Farming Robotic Vehicle,” International Conference on Embedded Systems (ICES 2014), 978-1-4799-5026-3, IEEE 2014.

[6] M. priyadarshini, Mrs. L. Sheela, "Command based self guided digging and seed sowing rover”, International Conference on Engineering Trends and Science \& Humanities, ISSN: 2348 - 8379, ICETSH-2015.

[7] AkhilaGollakota, M. B. shriniva, "Agribot - a multipurpose agricultural robot,” India conference (INDICON) 2011 Annual IEEE 978-1-4577-1110- 7, 1-4, IEEE 2011

[8] Fernando Alfredo AuatCheein and Ricardo Carelli "Agricultural Robotics: Unmanned Robotic Service Units in Agricultural Tasks"

[9] Kenneth J. Ayala”The 8051 Microcontroller and embedded systems" 2nd edition

[10] Muhammad Ali Mazidi”The 8051 Microcontroller and Embedded Systems using Assembly and C “ 2nd edition pearson publications

[11] Blackmore, S. (2007). A systems view of agricultural robotics. Precision Agriculture conference, Wageningen Academic Publishers, theNetherlands. pp. 23-31

[12] NithinP ,Shivaprakash " Multi purpose agricultural robot" International Journal of Engineering Research ISSN: 23196890 Volume No.5 pp: 1129 - 125420 May 2016. 